\title{
Evolução da saúde do trabalhador na perícia médica previdenciária no Brasil
}

\author{
Evolution of worker's health \\ in the social security medical examination in Brazil
}

\begin{abstract}
Afrânio Gomes Pinto Júnior ${ }^{1}$
Ana Maria Cheble Bahia Braga ${ }^{2}$

Amadeu Roselli-Cruz ${ }^{3}$
\end{abstract}

${ }^{1}$ Aps Cantagalo, Gbenin Petrópolis, Instituto Nacional do Seguro Social (INSS). Avenida Barão de Cantagalo 100, Centro. 28500-000 Cantagalo RJ afranio@ensp.fiocruz.br

${ }^{2}$ Centro de Estudos da Saúde do Trabalhador e Ecologia Humana, Escola Nacional de Saúde Pública, Fundação Oswaldo Cruz. ${ }^{3}$ Departamento de Farmacologia, Instituto de Ciências Biológicas, Universidade Federal de Minas Gerais.

\begin{abstract}
In order to analyze the practice of the social security medical examination starting from the introduction of the worker's health paradigms, data was gathered on the granting of social security disability benefits to assess worker illness based on notification of work-related accidents in the cement industries of Rio de Janeiro. From 2007 to 2009 there was only one notification, which involved a worker handling toxic waste instead of the energy matrix. However, the analysis revealed sources and mechanisms of illness overlooked in the social security medical examination, which is still focused on the one-causeonly logic of occupational medicine. To achieve the worker's health paradigms, changes are required to alter the way of conducting the social security medical examination, by re-establishing partnerships, training human resources, adopting epidemiological indicators, as well as setting and assessing social security goals that transcend the mere granting of disability benefits.
\end{abstract}

Key words Worker's health, Social security, Medical examination
Resumo Com o objetivo de analisar a prática da Perícia Médica Previdenciária a partir da introdução dos paradigmas da Saúde do Trabalhador, coletaram-se informações sobre a concessão de benefícios por incapacidade, avaliando o adoecimento pela geração da Comunicação de Acidente de Trabalho no Polo Cimenteiro do Rio de Janeiro. Entre 2007 e 2009 foi encontrada apenas uma notificação envolvendo o manuseio de resíduos tóxicos utilizados como substitutos de matriz energética embora a análise mostrasse fontes e mecanismos de adoecimento não considerados pela Perícia Médica, ainda centrada na lógica unicausal da Medicina do Trabalho. Para alcançar os paradigmas da Saúde do Trabalhador são necessárias mudanças na atuação da Perícia Médica, com o restabelecimento de parcerias, formação de recursos humanos, adoção de indicadores epidemiológicos, estabelecendo e avaliando metas que avancem para além da simples concessão de benefícios por incapacidade.

Palavras-chave Saúde do trabalhador, Previdência social, Perícia médica 


\section{Introdução}

A introdução da Saúde do Trabalhador no âmbito da Previdência Social Brasileira corresponde a um inequívoco avanço, possibilitando o entendimento e a intervenção sobre fatores extrabiológicos no processo saúde-doença. Estabelecido sobre os paradigmas da Medicina Social LatinoAmericana $^{1}$, o campo da Saúde do Trabalhador que vem sendo construído há mais de três décadas $^{2}$, amplia o olhar das Ciências da Saúde para além dos fenômenos biológicos, quando analisa as causas do adoecimento e de sua manutenção, assim como possibilidades de promoção da saúde e prevenção de agravos a partir de situações sociais, culturais, trabalhistas, ambientais, econômicas e políticas. Está inserido no contexto da Saúde Coletiva e ocupa o espaço criado pelo esgotamento dos modelos da Medicina do Trabalho e da Saúde Ocupacional, decorrente da perda de credibilidade junto aos trabalhadores além da dificuldade de diálogo com outras áreas afeitas ao processo saúde-doença ${ }^{3,4}$.

Surgido na mesma circunstância histórica que justificou a Reforma Sanitária ${ }^{5}$ e originou a estratégia de municipalização das ações de saúde, desenvolveu-se de forma heterogênea, segundo o interesse, a sensibilidade, a perseverança e a disposição de enfrentamento dos gestores. Incluída no rol das Vigilâncias, nasceu - da mesma forma que a Ambiental - competindo com as Vigilâncias Sanitária e Epidemiológica. Ao propor práticas como a "Intervenção Ética de Impacto" "tornou-se objeto de resistência organizada dos setores produtivos ${ }^{7}$.

Essas situações levaram a Saúde do Trabalhador a um período de introspecção acadêmica, resultando em maior amadurecimento teórico e qualificando-a como a melhor alternativa de intervenção, quando a Epidemiologia constatou o aumento de adoecimentos e mortes relacionadas ao trabalho.

Entretanto, a dificuldade de articulação de ações entre os Ministérios da Saúde, da Previdência Social e do Trabalho e Emprego, previstas na Constituição de 1988, impediram a efetivação de políticas públicas e sociais basilares para a efetiva implementação das ações de Saúde do Trabalhador ${ }^{8}$.

No ano de 2007 foi criada a Diretoria de Saúde do Trabalhador (DIRSAT) do Instituto Nacional do Seguro Social (INSS) ${ }^{9}$, cujo Regimento Interno, aprovado em 2009, prevê como atribuição da nova Diretoria, "desenvolver estudos voltados para o aperfeiçoamento das atividades médico periciais(...)" e propor "intercâmbio com órgãos governamentais visando o acompanhamento e o controle epidemiológico das doenças de maior prevalência nos benefícios por incapacidade", além de "planejar a especialização de ações para a melhoria da qualidade, correção e aprimoramento do reconhecimento de direitos aos benefícios por incapacidade previdenciários" 10 .

Migrar dos paradigmas que norteavam a antiga Coordenação de Gerenciamento de Benefícios por Incapacidade - por definição centrada na doença e suas consequências - para uma práxis que privilegia a Saúde, importa em longo percurso, quase uma conversão. A criação da DIRSAT deveria vir associada à incorporação dos conceitos da Saúde do Trabalhador, promovendo as ações necessárias à concretização dos propósitos do novo Regimento.

A análise do processo de trabalho dos peritos do INSS segue os paradigmas da Medicina do Trabalho, que postula a adaptação física e mental dos trabalhadores aos postos de trabalho ou tarefas, através de exames de seleção e de atividades "educativas", restrito aos conhecimentos e práticas da Ciência Médica.

No âmbito da Perícia Previdenciária, tal situação é evidenciada pela insensibilidade para lidar com questões socioambientais, culturais, econômicas, políticas e trabalhistas interferentes no processo saúde-doença-incapacidade, além da dificuldade de apropriação de estudos epidemiológicos para a compreensão das causas de incapacidade.

Neste artigo, busca-se analisar a prática da Perícia Médica da Previdência Social a partir da introdução dos conceitos norteadores da Saúde do Trabalhador, refletindo sobre o processo de trabalho na queima de resíduos tóxicos em fornos de cimento. O lócus de análise é o Polo Cimenteiro de Cantagalo, Rio de Janeiro, onde se encontram três indústrias envolvidas nessa prática.

\section{A queima de resíduos tóxicos em fornos de cimento e o adoecimento}

Com a justificativa da sustentabilidade, a indústria cimenteira nacional vem, desde 1991, substituindo carvão e óleo por resíduos industriais tóxicos, das mais diversas procedências e naturezas, para a geração de energia em seus fornos ${ }^{11}$. Inicialmente, privilegiava substâncias de elevado poder calorífico, entretanto, absorvendo a crescente oferta de passivos ambientais gerados pela indústria química, expande a alternativa de insumos destruídos termicamente, substituindo o processo, conhecido como coprocessamento, por outra atividade, chamada coincineração ${ }^{12}$. 
Coprocessamento e coincineração trazem riscos adicionais à produção de cimento, mais preocupantes do que aqueles encontrados nas indústrias geradoras dos resíduos, uma vez que, nestas, são conhecidos os insumos, as reações e os produtos, enquanto que nas atividades de queima a constituição química dos resíduos ou da mistura em que são agrupados ${ }^{12}$, raramente é definida em sua totalidade.

Essa condição impede a identificação toxicológica, inviabilizando medidas de prevenção, monitoramento ambiental e biológico, adequado tratamento de intoxicações e estabelecimento de nexo de causalidade entre a atividade laboral e as enfermidades que não apresentem efeitos agudos ${ }^{13}$.

A maioria das cimenteiras está instalada em pequenos municípios, onde o impacto ambiental do processo produtivo não é contestado. Tornam-se agentes de modificações do perfil produtivo e social, estabelecendo-se forte dependência da comunidade ${ }^{12}$.

Trabalhadores, moradores do entorno das fábricas, pessoas expostas ao longo das rotas de transporte que trazem os resíduos das indústrias geradoras até as fábricas de cimento, estão expostos a riscos tóxicos de natureza e consequências incertas. Assim, ao avaliar um segurado qualificado como mecânico em uma indústria de cimento o médico perito deverá estar ciente que aquele examinando encontra-se também exposto, aguda e cronicamente, a misturas de substâncias químicas de constituição imprecisa e potencial tóxico imponderável, além dos clássicos agentes e condições próprias da nosologia laboral do mecânico.

Pinto Júnior e Braga ${ }^{13}$ relataram situações em que trabalhadores empregados nessa atividade apontaram várias situações de risco e adoecimento. Admitiram a ocorrência de sinais e sintomas quando expostos a substâncias específicas, que cessavam com a interrupção do contato e tornavam a manifestar-se em novas exposições, medicando-se de forma sintomática e autoprescrita.

\section{Percurso metodológico}

O estudo exploratório proposto buscou analisar o processo concessório de Benefícios por Incapacidade pela Perícia Médica do INSS, a partir da avaliação das solicitações de benefício que tiveram início na Comunicação de Acidente de Trabalho (CAT) em um grupo sabidamente exposto a risco específico.

Acidentes e doenças do trabalho ou profissionais têm que ser comunicadas às autoridades através da CAT. O empregador deve preencher o formulário, havendo ou não afastamento, até o primeiro dia útil seguinte ao da ocorrência e, em caso de morte, de imediato à autoridade competente, sob pena de multa ${ }^{14}$.

Foram selecionados os municípios que integram o Polo Cimenteiro do Rio de Janeiro (Cantagalo, Macuco e Cordeiro), tendo como referencial os anos de 2007, 2008 e 2009. Para a análise, considerou-se o processo de trabalho focalizado nas cimenteiras, o adoecimento por causa laboral, faixa etária e exposição a resíduos tóxicos.

A discussão se faz a partir da coleta de informações nos processos de concessão de benefício avaliando relatos de fatos ocorridos, pareceres dos médicos peritos do INSS, paradigmas e práticas da Saúde do Trabalhador, à luz da literatura científica nacional, utilizando os termos "saúde do trabalhador", "Previdência Social” e "perícia médica” no período de 2005 a 2010, disponível nas bases de dados eletrônicas Lilacs, SciELO, Cochrane e Medline. Não obstante, publicações anteriores foram utilizadas para compor a evolução do conhecimento na área.

\section{Resultados e discussão}

Embora evidente o nexo de causalidade entre adoecimento e exposição ocupacional a resíduos tóxicos em vários casos, somente uma notificação por Comunicações de Acidentes e Doenças do Trabalho foi encontrada nas Agências da Previdência Social que atendem à população estudada ${ }^{12}$.

Referia-se a queimadura dos membros inferiores de um trabalhador, atingido por resíduos químicos extravasado de um tambor danificado. Após ter lavado a área contaminada e trocado o uniforme, persistindo ardência cutânea, procurou o ambulatório da empresa, sendo tratado com "creme", também sem resultado satisfatório. Poucas horas após, procurou Pronto Socorro com náusea, vômitos e cefaléia, interpretados como sinais de intoxicação sistêmica, tratados sintomaticamente, sem emissão de notificação à autoridade sanitária. Três dias após foi internado para debridamento cirúrgico das queimaduras, sob narcose. A Comunicação de Acidente do Trabalho emitida 10 dias após o evento apontava "produto químico" como agente causador, impedindo o rastreamento de impacto sistêmico específico, a médio e longo prazo, assim como dificultou a determinação do nexo de causalidade ${ }^{12}$.

Esse caso foi formalmente comunicado ao SST, apontado como passivo de medidas especi- 
ais. Foi proposta fiscalização conjunta, com o Ministério do Trabalho e o Sistema Único de Saúde, de forma a se dimensionar características e magnitude dos possíveis riscos do processo produtivo à Saúde Coletiva, seguindo metodologia de Vigilância à Saúde do Trabalhador. Entretanto, a correspondência enviada, e ratificada, em nada resultou.

Cinco anos após o Acidente de Trabalho, o mesmo segurado volta a pleitear benefício por incapacidade, desta vez por pós-operatório de varizes restritas às áreas queimadas, complicado com dor e edemas persistentes, incomumente associados ao procedimento. Admitindo que o requerente foge ao perfil do varicoso habitual, e atribuindo a dor atípica a possível fibrose pósinflamatória da adventícia dos vasos removidos, por onde circularam os tóxicos que provocaram queimaduras dos tecidos expostos e intoxicação sistêmica, estabeleceu-se Nexo Técnico Epidemiológico (NTEP), sendo concedido Auxílio Doença Acidentário.

Imediatamente, a empresa contestou o NTEP através de recurso à Junta de Recursos da Previdência Social, alegando sobrepeso e ocorrência de varizes em familiares do trabalhador, deixando de considerar a fisiopatologia das lesões causadas pelo acidente, e que $83,9 \%$ dos casos de varizes ocorrem em mulheres ${ }^{15}$, acima dos 50 anos de idade.

Em despacho no processo de contestação do NTEP, o perito que analisou o pleito da empresa expressou dúvida quanto à natureza química dos "produtos" (que, conceitualmente, diferem de resíduos), sobre o procedimento cirúrgico realizado e a gravidade das queimaduras sofridas, e solicitou à empresa que apresentasse o Perfil Profissiográfico Previdenciário.

Em resposta, a empresa informou que, entre dezembro de 2005 e julho de 2009, o trabalhador esteve exposto a 5 substâncias e 3 elementos químicos, sempre nas mesmas concentrações, o que se constitui em absurdo, considerando-se a natureza da atividade profissional exercida pelo segurado. Admite que não utiliza Equipamento de Proteção Coletiva e atribui eficiência a máscara respiratória, embora a contaminação tenha se feito através da pele das pernas. Também não aponta resultado de monitorização biológica de exposição ou efeito realizada no mesmo período.

Em parecer no processo de contestação de NTEP, o perito relata que não foram anexadas informações sobre a patologia apresentada e considerada como complicação decorrente do acidente de trabalho e contesta a gravidade das queima- duras que não examinou. Finalmente, atribui as queixas do segurado ao excesso de peso e ao ortostatismo prolongado e conclui que não há como comprovar relação direta entre as queimaduras apresentadas e o desenvolvimento de varizes em membros inferiores, não podendo caracterizar benefício acidentário.

Partindo da premissa que "só se diagnostica o que se conhece", o médico perito necessita conhecer profundamente o perfil produtivo da região atendida pela APS onde trabalha. Precisa conhecer as circunstâncias da produção, o processo de trabalho, os gestos profissionais, os riscos e patologias inerentes à atividade de cada segurado que atende, para estabelecer a causalidade da enfermidade e o respectivo nexo.

Assim como a indústria do cimento, vários ramos de negócios têm mudado seus processos produtivos sem que isso seja noticiado, deixando médicos peritos desguarnecidos de informações imprescindíveis ao julgamento. Se um trabalhador empregado em uma fábrica de cimento desenvolve câncer, hepatopatia, nefropatia, doença metabólica ou hematológica, dificilmente o perito associará a enfermidade a exposições diárias a misturas de substâncias químicas desconhecidas, se não tiver ciência de que a indústria que o emprega adota - assim como, o que é - o coprocessamento de resíduos químicos.

A política de saúde de boa parte das empresas encontra limitações na lógica capitalista que rege o mercado em que estão inseridas. Abordar $o$ adoecimento do trabalhador gera, naturalmente, questionamentos sobre suas causas. Contudo, a necessidade de zelar pela imagem provoca comportamentos, não raro, falaciosos. Acidentes e adoecimentos comprometem a imagem da empresa entre seus pares, no cenário público, nos mercados consumidor e acionário.

Tal fato tem gerado uma prática que contraria a lei, o direito dos trabalhadores, a verdade: não se notificam acidentes e adoecimentos que não resultem em afastamentos previdenciários, o que é facilmente observável ao se analisar os acidentes informados através de Comunicações de Acidentes do Trabalho ${ }^{12}$. Contrariando o que todos conhecem, predominam notificações de acidentes de maior sobre os de menor gravidade, acidentes com afastamento sobre os que não justificam faltas ao trabalho.

Várias empresas adotam programas que buscam a eliminação de acidentes ${ }^{16}$, entretanto, não raro, geram situações que vitimam o trabalhador duplamente: primeiro pela doença ou acidente; segundo por discriminá-lo como gerador 
da condição que derrubou a meta de "Acidente Zero". Existem casos em que a participação nos lucros da empresa é condicionada a metas de acidentabilidade, imputando aos empregados a integralidade da culpa por não alcançá-la. Qual seria o trabalhador que não se constrangeria ao ser identificado como causador da perda pecuniária imposta a seus colegas?

O Movimento Sindical não vem sendo capaz de se contrapor à precarização das relações de trabalho, e tem focado sua atuação na política salarial, descuidando de questões relativas à Saú$\mathrm{de}^{17}$. Embora os sindicatos devam ser comunicados por ocasião de agravos gerados pelo trabalho, não questionam a inversão da lógica de notificações, não buscam parcerias para discutir o impacto do trabalho no eixo saúde-doença, não se ocupam da construção de política de manutenção da saúde e eliminação de riscos a partir da reformulação do processo de trabalho.

Ao Sistema Único de Saúde, segundo a Lei no $8.080 / 1990^{18}$, cabe zelar pela "promoção, proteção, assistência, recuperação e reabilitação da saúde dos trabalhadores", através da "normatização, fiscalização e controle da produção, extração, armazenamento, transporte, distribuição e manuseio de substâncias, de produtos, de máquinas e de equipamentos que apresentam riscos". Integrante da cadeia de notificação e investigação de agravos atribuídos ao trabalho tem atuação restrita à assistência aos casos de maior complexidade, já que lesões de menor significância são atendidas nos ambulatórios das empresas $^{3}$. Ainda assim, se o médico que presta o atendimento infere nexo de causalidade, frequentemente, não emite Comunicação de Acidente do Trabalho, deixando de acionar os mecanismos de vigilância.

Durante os anos seguintes à publicação da Lei Orgânica da Saúde, as novas atribuições do setor Saúde, que envolvem intervenção em locais de trabalho, sofreram forte resistência da fiscalização do Ministério do Trabalho, até então hegemônica naquelas ações ${ }^{19}$. Atendendo exclusivamente aos interesses do patronato, essa postura impediu o desenvolvimento da política de Saúde do Trabalhador no SUS, que só recentemente se recupera, ainda de forma incipiente e irregular, a partir da implantação dos Centros de Referência em Saúde do Trabalhador. Insistindo em formas de produção focadas exclusivamente no lucro ${ }^{20}$, empresas provocam situações de imenso desgaste para peritos da Previdência Social, que, no dizer de muitos, não dão benefício a quem "pagou" para tê-lo.
Esse juízo, ainda comum entre empresários e médicos, faz do INSS o desaguadouro "natural" de segurados avaliados como incapazes para o exercício da profissão, embora possam, com sua experiência, contribuir para a otimização de tarefas e postos de trabalho, e, não raro, executar as mesmas funções, desde que modificado o processo produtivo. Despreza-se o saber do trabalhador, insistindo-se em submetê-lo, quando adoecido, ao imobilizante título de "paciente".

A Previdência Social, por sua vez, reduz o registro de Acidentes do Trabalho à mera atividade cartorial, perdendo a oportunidade de tratá-los epidemiologicamente e provocar as ações cabíveis. O Nexo Técnico Epidemiológico Previdenciário, que, sem dúvida, aproximou da realidade o número de agravos relacionados às condições de trabalho, ao menos por ora, só trouxe a vantagem da garantia de estabilidade no emprego após a alta do benefício aos segurados. Ainda assim, insatisfeitas pela majoração das alíquotas de contribuição, as empresas recorrem à impugnação. No caso relatado, a empresa alcançou seu intento, a partir de parecer favorável produzido sem que o trabalhador tivesse tido a oportunidade de se manifestar, acatando argumentos refutáveis, desprezando a experiência de perito especialista no assunto, e contrariando, formalmente, os postulados da Saúde do Trabalhador.

Entre a Previdência Social e o SUS também se identificam conflitos de entendimentos ${ }^{21}$. Têm sido frequentes relatos de situações apontadas pelos Cerest de adoecimento por causa laboral, não endossado pela Perícia Médica do INSS.

O distanciamento entre fiscalização do Ministério do Trabalho e Emprego, Perícia Médica do INSS e Cerest do SUS é fato, inviabiliza o olhar epidemiológico - base para qualquer intervenção - e constitui-se em sério empecilho à consolidação da política nacional de Saúde do Trabalhador8.

$\mathrm{O}$ adoecimento tem determinantes sociais; a Previdência, em tese, é social. Logo, a avaliação da incapacidade deve considerar elementos sociais. Os parágrafos anteriores demonstram situações de desproteção social aos trabalhadores, vitimados pelo adoecimento e pela omissão dos organismos concebidos para protegê-los.

O elemento de trabalho da Previdência é a doença, e não a saúde, e esse modelo dá claros sinais de esgotamento. Aos peritos são impostas metas quantitativas de produção, que não invertem a tendência ao adoecimento, logo não atendem àquilo que a Sociedade necessita. Ao criar a Diretoria de Saúde do Trabalhador, o INSS deu a entender que fazia uma opção pela mudança. 
Repensar a mecânica do adoecimento para além de suas causas biológicas, supre uma lacuna que o pensamento médico secularmente não valorizou. Não há disciplina ou profissão que, isoladamente, seja capaz de compreender plenamente e intervir adequadamente sobre todas as circunstâncias da relação trabalho-saúde-doença. Para alcançar este objetivo, será necessária a convergência de experiências e o estabelecimento de parceirias do INSS com outras instituições.

Favorecem o adoecimento: baixa escolaridade, poucas oportunidades de trabalho, falta e ocultação de informações, cerceamento do saber prático dos trabalhadores, pobreza. Nenhuma dessas condições são médicas, mas sua superação é essencial à promoção e proteção à saúde.

As práticas de Vigilância em Saúde úteis à identificação de mecanismos de adoecimento, de modo ideal desenvolvidas por equipes multiprofissionais, priorizando ações de alcance coletivo e controle de riscos na(s) fonte(s), planejadas a partir de indicadores epidemiológicos ${ }^{19}$, não integraram o conjunto de ações da Perícia Médica. Mesmo quando provocada a fazê-lo, não tem instrumentos para transformar suas conclusões em ações concretas para a promoção de saúde.

As empresas apregoam respeito a valores ambientais e sociais, intitulando-se sustentáveis, contudo, desprezam o Princípio da Precaução ${ }^{22}$, adotando as incertezas dos processos produtivos a favor dos interesses do Capital, relegando a saúde das populações a plano secundário ${ }^{23}$.

A lógica de atribuição de culpas confere ao trabalhador responsabilidade pelo adoecimento do qual é vítima, uma vez que, não raro, a ele é confiada a organização do local e o planejamento do próprio trabalho ${ }^{24}$. Paralelamente, desconsideram-se elementos fundamentais na gênese do acidente ou adoecimento, como a pressão de produção, as horas extras, as ameaças de demissão, os prêmios por produtividade, a distância e as dificuldades de acesso entre residência e emprego, baixos salários, busca por outras fontes de renda, preocupação com situações pessoais ou familiares.

A perícia encontra o trabalhador fragilizado. Adoecido, não raro com dor, humilhado pela perda da capacidade produtiva que o diferencia de seus pares, desacompanhado das entidades que o representam, pressionado ante a autoridade do perito, que tem o poder de conceder ou negar-lhe o benefício, o trabalhador segurado adota postura submissa frente àquele que julgará seu pleito. Já recebeu uma primeira avaliação do médico da empresa, que o considerou inapto para o traba- lho. Sabe que, se não receber o benefício, se tornará ponto de atrito entre duas autoridades com posições contrárias, que não discutem pessoalmente, e o tornam protagonista/mensageiro de um assunto que não domina. Nessas circunstâncias, dificilmente presta informação cujo foco não seja exclusivamente seu quadro clínico e incapacidade. Caberá ao médico perito, assim como ao médico da empresa, buscar as causas anteriores, determinantes do adoecimento e incapacidade, bem como apontá-las às autoridades responsáveis por ações que as revertam.

O Perfil Profissiográfico Previdenciário, concebido como via de informação entre empresa e Previdência, quando usado, traz informações aquém daquelas que efetivamente explicitam o risco de adoecimento. No caso descrito, por exemplo, expressa exposição a poucas substâncias químicas de composição estável, quando a natureza da atividade pressupõe exposição a misturas de composição inconstante. Laudos Técnicos das Condições de Trabalho, Programas de Prevenção de Riscos Ambientais e Programas de Controle Médico de Saúde Ocupacional, também ferramentas para a identificação daquilo que a empresa aponta como risco à saúde dos trabalhadores e ambiente, só serão úteis se tomadas sob olhar crítico de profissionais preparados para interpretá-las e, sempre que necessário, contestá-las.

A história da Previdência Social não revela protagonismo de ações de prevenção de doenças e/ou promoção à Saúde do Trabalhador. As lutas contra o jateamento de areia, benzenismo, asbestose, intoxicações por agrotóxicos e tantas outras, foram travadas no campo da Saúde, e se hoje existe alguma ação previdenciária de apoio a portadores dessas nosologias, não nasceu exatamente da iniciativa do INSS.

É corrente entre profissionais de saúde dos municípios de Cantagalo, Macuco e Cordeiro, que compõem o Polo Cimenteiro Fluminense, a percepção de maior prevalência de enfermidades respiratórias e neoplásicas, desproporcionalmente maiores que em outros municípios da região, mais distantes das indústrias cimenteiras. Essas observações, confirmadas pelo Departamento de Informática do Sistema Único de Saúde (Datasus), ao menos sugerem a possibilidade de correlação ambiental. Contudo, somente agora, 20 anos após o início do coprocessamento e 40 após a implantação das fábricas de cimento na região, por iniciativa do setor saúde, começam a serem organizados estudos buscando verificar tais hipóteses. A Previdência, detentora do maior banco de dados sobre enfermidades incapacitantes 
do país, chamada a participar do estudo, sequer respondeu às proposições da Saúde.

Souza et al..$^{25}$, estudando correlação entre benefícios previdenciários e acidentários concedidos pelo INSS no Estado da Bahia, apontam que $3,1 \%$ do total correspondem a doenças relacionadas ao trabalho. Entretanto, observando-se o quadro que distribui casos por aparelhos e sistemas, podermos questionar quantas daquelas enfermidades neuropsiquiátricas não seriam desencadeadas por estresse profissional; quantas neoplasias, doenças hematológicas, renais, hepáticas não estariam primariamente associadas a exposições a produtos químicos; quantas endocrinopatias não seriam secundárias a disrupção por agentes ambientais. $O$ fato é que não é prática corrente entre médicos - peritos ou não - colher anamnese ocupacional, assim como não recebem formação/atualização em Toxicologia.

A Perícia Médica Previdenciária, classicamente reparadora e eventualmente reabilitadora, está, até aqui, ocupada em absorver a demanda de segurados que desejam ter seus pleitos atendidos, independentemente de seus direitos. Nessa perspectiva compreende-se a desmotivação dos médicos peritos, que praticam uma judicatura em que arbitram a concessão de benefícios, sem que lhes sejam dadas oportunidades de contribuir com o planejamento de uma política efetivamente previdenciária. Mesmo quando conseguem identificar oportunidades de interferir nos processos que geram adoecimento, são tolhidos pela burocracia que limita sua atuação ao trabalho prescrito ${ }^{26}$.

A Reabilitação Profissional carece de proatividade. Funciona seguindo modelos pré-estabelecidos, nem sempre adequados à realidade local, limitando a criatividade daqueles que tentam devolver segurados para um mercado de trabalho fortemente competitivo, enfrentando resistência das empresas. Da mesma forma que a Perícia Médica, não conhece efetivamente os processos de trabalho. Acata passivamente frequentes negativas às suas proposições, além do desrespeito de ter correspondências ignoradas. Neste clima, os segurados percebem a vulnerabilidade da relação interinstitucional, e preferem a comodidade da manutenção do benefício.

$\mathrm{O}$ médico perito não conhece o produto do seu trabalho. A menos que as produza pessoalmente, não tem acesso a estatísticas que apontem as nosologias determinantes de incapacidade no nível em que atua. Se estudos desta natureza são realizados, não são divulgados. Essa situação condena a atuação do médico perito a em- pirismo frustrante. Se trabalhasse sobre bases epidemiológicas teria percepção mais aproximada das condições patogênicas, também geradoras de benefícios previdenciários, podendo avançar na direção de propor medidas preventivas e saneadoras. Em contraposição, é exposto à apreciação da comunidade a partir de índices exclusivamente voltados para a avaliação do tempo gasto para a concessão de benefícios. Esperar mudanças da lógica da perícia de forma a atuar eficientemente segundo os paradigmas da Saúde do Trabalhador sem rever sua (arcaica) estrutura seria ingênuo.

O médico é membro nato da Saúde do Trabalhador, que, por princípio, é multiprofissional. Entretanto, acreditar, com toda a história de poder concedida à classe pela sociedade, que não existirá resistência à quebra de sua hegemonia, também seria ingenuidade. No momento, tramita no Congresso Nacional o Projeto de Lei $7.200 / 2010$, que propõe a alteração do $\$ 1^{\circ}$ da Lei 8.213, de 24 de julho de $1991^{14}$, no sentido de ampliar a participação de profissionais de saúde na perícia da Previdência Social, estendendo a responsabilidade de avaliar incapacidade a psicólogos, fisioterapeutas, terapeutas ocupacionais e assistentes sociais do quadro do INSS. Essa medida, que soa "interessante" segundo a lógica da Saúde do Trabalhador, recebe críticas da Associação Nacional dos Médicos Peritos.

O INSS não dispõe de profissionais preparados para dar às Seções de Saúde do Trabalhador o perfil que terão que adotar para atender àquilo que delas se espera. Segundo Minayo-Gomez ${ }^{2}$, Saúde do Trabalhador é arena de conflitos e entendimentos formalizados ou pactuados entre empresas, trabalhadores e instituições públicas frente a situações-problema. Como negociar sem indicadores epidemiológicos que expliquem o adoecimento regional, sem parceria com as áreas sindical, de saúde, de trabalho, academia? Como negociar sem autonomia, sem delegação de competência, já que contatos interinstitucionais são prerrogativas de instâncias hierárquicas superiores?

\section{Considerações finais}

Certamente, o INSS não deixará sua vocação de conceder benefícios por incapacidade e não se tornará exatamente um promotor de saúde. Entretanto, dando tratamento epidemiológico à imensa gama de informações sobre adoecimento que é capaz de captar, pode - e deve - contribuir de forma concreta para que políticas públi- 
cas sejam desenvolvidas, implementadas e avaliadas, de forma a se buscar a reversão das tendências de adoecimento.

Será necessário estabelecer parcerias com os Cerest, fiscalização do Ministério do Trabalho e Emprego, e, sobretudo, com Sindicatos e Academia, onde se encontram o saber empírico e o conhecimento sistematizado sobre o assunto.

O conhecimento é evolutivo, e não flui sem que canais sejam estabelecidos. Resultados de todas as ações, considerando-se a multiplicidade de perfis de produção e de adoecimento existentes no país, precisam ser compartilhados.

Por certo, tantas novas atribuições levariam à necessidade de adequação do quadro de servidores. Entretanto, a interação dos recursos do SUS, Previdência e Ministério do Trabalho, através da integração de olhares, pode desfazer áreas de sobreposição de atribuições, racionalizar custos, somando conhecimentos e multiplicando ações. Também as melhorias dos ambientes e processos de trabalho reduziriam gastos com assistência, reabilitação, pagamentos de benefícios por incapacidade.

Para garantir organicidade das mudanças necessárias, bem como a perenidade dos estudos que devem fundamentá-las, seria desejável que a Previdência Social, seguindo o exemplo dos Ministérios do Trabalho e Emprego e da Saúde que criaram, respectivamente, a Fundacentro e o Centro de Estudos da Saúde do Trabalhador e Ecologia Humana - CESTEH/ENSP/Fiocruz, montasse uma estrutura que congregasse pesquisadores - muitos já integrantes e dispersos no quadro funcional do INSS - dedicados à produção científica voltada à melhoria dos resultados institucionais, sem dúvida objetivo do Estado e da Sociedade.

Esperamos que o conjunto destas propostas, eticamente necessárias e economicamente viáveis, contribua para a consolidação da Saúde do Trabalhador no âmbito da Previdência Social Brasileira, aproximando seus segurados da cidadania a que têm direito.

À Perícia Médica caberá protagonizar a transição do modelo. Com sua vocação social tem papel ético que transcende a simples interpretação de incapacidade para o trabalho, fundamental na mudança, por ser a única instituição pública que tem, atualmente, elementos para identificar o impacto da atividade laboral no processo saúde-doença, já que, cada vez mais a assistência médica é controlada pelos empregadores.

Entretanto, transcorridos mais de 3 anos desde a publicação da "boa nova", não foram percebidos os produtos da mudança, e, naturalmente, surgem dúvidas se a proposta é efetiva ou meramente retórica.

\section{Colaboradores}

AG Pinto Júnior, AMCB Braga e A Roselli-Cruz participaram igualmente de todas as etapas de elaboração do artigo. 


\section{Referências}

1. Laurell AC, Noriega M. Processo de produção e saúde: trabalho e desgaste operário. São Paulo: CEBES, Editora Hucitec; 1989.

2. Minayo-Gomez C, Thedim-Costa, SMF. A construção do campo da saúde do trabalhador: percurso e dilemas. Cad Saude Publica 1997; 13(2):21-32.

3. Mendes R, Dias EC. Da medicina do trabalho à saúde do trabalhador. Rev Saude Publica 1991; 25(5): 341-349.

4. Lacaz FAC. O campo Saúde do Trabalhador: resgatando conhecimentos e práticas sobre as relações trabalho-saúde. Cad Saude Publica 2007; 23(4):757766.

5. Lacaz FAC. Reforma Sanitária e saúde do trabalhador. Saúde Soc 1994; 3(1):41-59.

6. Vasconcellos LF, Ribeiro FSN. Investigação epidemiológica e intervenção sanitária em saúde do trabalhador: o planejamento segundo bases operacionais. Cad Saude Publica 1997; 13(2):269-275.

7. Fernandes L, Porto MF. Understanding risks in socially vulnerable contexts: the case of waste burning in cement kilns in Brazil. Safety Science 2006; 44(3):241-257.

8. Gomez CM, Lacaz FAC. Saúde do trabalhador: novas-velhas questões. Cien Saude Colet 2005; 10(4):797807.

9. Brasil. Ministério da Previdência Social. Decreto $\mathrm{n}^{\circ}$ 6.042, de 12 de fevereiro de 2007. Altera o Regulamento da Previdência Social, aprovado pelo Decreto $\mathrm{n}^{\circ} 3.048$, de 6 de maio de 1999, disciplina a aplicação, acompanhamento e avaliação do Fator Acidentário de Prevenção (FAP) e do Nexo Técnico Epidemiológico, e dá outras providências. Diário Oficial da União 2007; 12 fev.

10. Brasil. Ministério da Previdência Social. Portaria $\mathrm{n}^{\circ}$ 296, de 09 de novembro de 2009. Aprova o Regimento Interno do Instituto Nacional do Seguro Social (INSS). Diário Oficial da União 2009; 10 nov.

11. Associação Brasileira de Cimentos Portland (ABCP). Coprocessamento. [site na Internet]. [acessado 2010 jul 17]. Disponível em: http://www.abcp.org.br/ conteudo/wp-content/uploads/2010/06/folder_ coprocessamento.pdf

12. Pinto Júnior AG. Condições de trabalho e saúde de trabalhadores na queima de resíduos tóxicos em fornos de cimenteiras de Cantagalo, RJ [dissertação]. Rio de Janeiro (RJ): Fiocruz; 2009.

13. Pinto Junior AG, Braga AMCB. Trabalho e saúde: a atividade da queima de resíduos tóxicos em fornos de cimenteiras de Cantagalo, Rio de Janeiro. Cien Saude Colet 2009; 14(6):2005-2014.

14. Brasil. Lei no 8.213 , de 24 de julho de 1991. Dispõe sobre os Planos de Benefícios da Previdência Social e dá outras providências. Diário Oficial da União 1991; 25 jul.
15. Andrade ART, Pitta GBB, Castro AA, Miranda Júnior F. Avaliação do refluxo venoso superficial ao mapeamento dúplex em portadores de varizes primárias de membros inferiores: correlação com a gravidade clínica da classificação CEAP. J Vasc Bras 2009; 8(1):14-20.

16. Antunes Lima, FP. Ações coordenadas em saúde do trabalhador: uma proposta de atuação supra-institucional. Rev Bras Saúde Ocup 2009; 34(119):67-78.

17. Pochmann M. Desafios atuais do sindicalismo brasileiro. In: Toledo EG, compilador. Sindicatos y nuevos movimentos sociales en América Latina. Buenos Aires: CLACSO; 2005. p. 163-180.

18. Brasil. Lei Federal no 8.080 , de 19 de setembro de 1990. Dispõe sobre as condições para a promoção, prevenção e recuperação da saúde, a organização e o funcionamento dos serviços correspondentes e dá outras providências. Diário Oficial da União 1990; 20 set.

19. Machado JMH. A propósito da Vigilância em Saúde do Trabalhador. Cien Saude Colet 2005; 10(4):987992.

20. Oddone I, Marri G, Glória S, Briante G, Chiatella M. Ambiente de trabalho: a luta dos trabalhadores pela saúde. São Paulo: Hucitec; 1986.

21. Takahashi MABC, Iguti AM. As mudanças nas práticas de reabilitação profissional da Previdência Social no Brasil: modernização ou enfraquecimento da proteção social? Cad Saude Publica 2008; 24(11): 2661-2670.

22. Lacey H. O princípio de precaução e a autonomia da ciência. Sci Stud 2006; 4(3):373-392.

23. Augusto LGS, Freitas CM. O Princípio da Precaução no uso de indicadores de riscos químicos ambientais em saúde do trabalhador. Cien Saude Colet 1998; 3(2):85-95.

24. Binder MCP, Almeida IM. Estudo de caso de dois acidentes do trabalho investigados com o método de árvore de causas. Cad Saude Publica 1997; 13(4): 749-760.

25. Souza NSS, Santana VS, Albuquerque-Oliveira PR, Barbosa-Branco A. Doenças do trabalho e benefícios previdenciários relacionados à saúde, Bahia. Rev Saude Publica 2008; 42(4):630-638.

26. Ferreira MC. Bem Estar: Equilíbrio entre a Cultura do Trabalho Prescrito e a Cultura do Trabalho Real. In: Álvaro Tamaio, organizador. Cultura Organizacional e Saúde. São Paulo: Ed. Artmed; 2004.

Artigo apresentado em 13/07/2011

Aprovado em 25/10/2011

Versão final apresentada em 05/11/2011 
